\title{
Numerical Tests on Zonal Disintegration within Rockmass Around Deep Tunnel under Dynamic Disturbance
}

\author{
Chunchun Chen, Yujun Zuo \\ Research Center for Numerical Test of Material Failure \\ Dalian University \\ Dalian,China
}

\begin{abstract}
Numerical tests on three-dimensional rock samples containing hole were carried out with finite element software ANSYS to investigate the mechanism of zonal disintegration within surrounding rockmass around deep circular tunnel under dynamic disturbance. Numerical tests presented the distribution of stress and deformation and visualized zonal disintegration phenomenon of rockmass around deep semiarched tunnel under dynamic loads. The simulation results indicate that zonal disintegration phenomenon may occur, when superposition value of high ground stress and dynamic disturbance satisfies a certain condition.
\end{abstract}

Keywords-Rockmass around deep tunnel, Zonal disintegration, Numerical test, Dynamic disturbance

\section{INTRODUCTION}

At present, with the deep excavation of deep rock engineering responsed a series of new scientific phenomena, such as zonal disintegration phenomena and rock burst, these new scientific phenomena compared with shallow rock engineering has different characteristics. Thereinto, the zonal disintegration phenomena [2] is in the excavation of deep rock roadway or cavern, in its sides and in front of work of the surrounding rock produced successive alternate ruptured zone and unruptured zone phenomenon. This phenomenon have found in many foreign deep mines[3-4]. These deep problem is no longer the linear superposition factors science system which we are familiar with the factors, but nonlinear science system, caused great concern of the international rock mechanics engineering field experts and scholars, become the great interest in this field research hot spot in recent years[5].

Current research mainly focuses on deep protolith stress field, physical mechanics characteristic of buried rock of the influence of zonal disintegration mechanism, and made some important achievements[6-7]. But the present study most is given priority to static, dynamic loads less consider to under the influence of the deep stress rock. According to the zonal disintegration loading model who GuJinCai etc[8], Namely to parallel hole axis for the first principal stress and the tunnel axis loading exert dynamic disturbances. Numerical experiment and analysis were carried out with finite element software ANSYS to the mechanism of zonal disintegration within surrounding rockmass around deep under dynamic disturbance.

\author{
Dekang Zhu \\ Research Center for Numerical Test of Material Failure \\ Dalian University \\ Dalian,China
}

\section{NUMERICAL COMPUTATION MODEL}

\section{A. Rock material state equation}

In load impact the rock achieve easily one-dimension strain state, Using Johnson_Holmquist_Concrete material model to describes the dynamic process[9]. JHC model suitable for large strain, high strain and high pressure conditions, Rock's equivalent strength related to stress, strain rate and damage, its constitutive relation may be described as:

$$
\sigma^{*}=\left[A(1-D)+B\left(p^{*_{N}}\right)\right]\left(1-c \ln \dot{\varepsilon}^{*}\right)
$$

There: $\sigma^{*}$ for regularized stress, $\sigma^{*}=\sigma / f_{c}, \sigma$ for in the actual force of rock impact process, $f_{c}$ for quasi-static uniaxial compressive strength; $D$ for rock's damage

parameter; $p^{*}=p / f_{c}$, there $p$ for pressure; $\varepsilon^{*}=\dot{\varepsilon} \dot{\varepsilon_{0}}$ for dimensionless strain rate; $A$ nomal viscous coefficient; $B$ for nomal pressure sclerosis coefficient; $C$ for strain rate coefficient.

JHC model mainly by the failure criterion of the von Mises yield criterion, Its equivalent stress for:

$$
\sigma_{e}=\sqrt{\frac{1}{2}\left[\left(\sigma_{1}-\sigma_{2}\right)^{2}+\left(\sigma_{2}-\sigma_{3}\right)^{2}+\left(\sigma_{1}-\sigma_{3}\right)^{2}\right]}
$$

Among them, $\sigma_{1}, \sigma_{2}, \sigma_{3}$ for three principal stress. Rock material parameters see table I.

\begin{tabular}{|c|c|c|c|}
\hline $\begin{array}{c}\text { Material } \\
\text { Parameters }\end{array}$ & $\begin{array}{c}\text { Parameter } \\
\text { s }\end{array}$ & $\begin{array}{c}\text { Material } \\
\text { Parameters }\end{array}$ & Parameters \\
\hline Density $(\mathrm{g} / \mathrm{cm})$ & 2.6 & $\mathrm{D}$ & 0.05 \\
\hline Poisson's ratio & 0.25 & fc & 0.072 \\
\hline $\begin{array}{l}\text { Elastic modulus } \\
\text { E/GPa }\end{array}$ & 30 & $\mathrm{p} / \mathrm{GPa}$ & 0.016 \\
\hline$f^{*} c$ & 0.072 & $\varepsilon_{0}$ & $1.0 \times 10-6$ \\
\hline $\mathrm{A}$ & 0.8 & $\mathrm{c}$ & 0.007 \\
\hline $\mathrm{B}$ & 1.6 & $\mathrm{~N}$ & 0.6 \\
\hline
\end{tabular}

TABLE I. ROCK MATERIAL PARAMETERS

\section{B. Model parameters}

Taking a mine as the research background, buried deep $1050 \mathrm{~m}$, Consider Saint-Venant's Principle, take the size of roadway surrounding rock for 5-6 times, the size of ANSYS numerical calculation model is $25 \mathrm{~m} \times 25 \mathrm{~m} \times 25 \mathrm{~m}$, tunnel located in the middle of the model, the upper part is a semicircle arch tunnel diameter was $5 \mathrm{~m}$. Initial geostress for 
24.5 $\mathrm{MPa}$, the finite element model have 11,000 units, 12,726 nodes. Uniaxial compressive strength is $\sigma_{c}=26 \mathrm{MPa}$, and the uniaxial compressive strength corresponding limit strain for $\mathcal{E}_{c}=2.3 \mathrm{e}-3$, the uniaxial tensile strength $\sigma_{t}=2.52 \mathrm{Mpa}$. Loading boundary conditions as follows: Model left and right, up and down boundary load displacement constraints, the axial load impact loading, Calculation model shown as shown in figure 1.

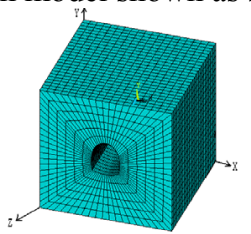

(a)

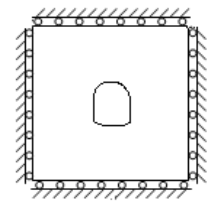

(b)

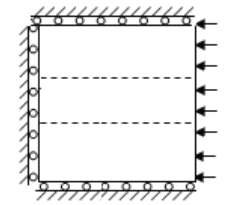

(c)

Figure 1. (a) ANSYS model (b) $x-y$ direction loading boundary conditions (c) y-z direction loading boundary conditions

Figure.1 ANSYS model and loading conditions

Load exert: along $\mathrm{z}$ direction on the $\mathrm{z}=25 \mathrm{~m}$ surface imposed the static stress. On the basis of static load of loading, additional as impact stress load shows figure2. Dynamic load and the static load applied in the same direction, all along the $\mathrm{z}$ axis direction. Define impact load produce to stress around border, the calculation model around and underside defined as no reflection boundary conditions. Figure 2 shows dynamic load, each point corresponds to a load step, Excavation disturbance unloading time for $10 \mathrm{~ms}$, output files for 100 steps. Output file types of ANSYS and LS-DYNA. Namely in the calculation of simultaneous output for ANSYS and LS-POST postprocessing result file.

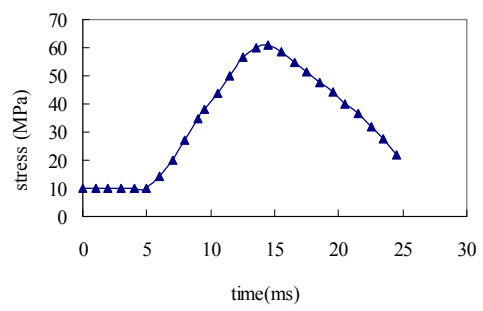

Figure 2. Stress-time curve

\section{Unit selection and contact problem}

In LS-DYNA, roadway model of simulating along the thickness direction using fully integral and because of fully integral, does not exist the hourglass numerical problems and too soft. Under load between possible contact interface, adopts automatic surface and surface contact algorithm, the program will automatically in the calculation of contact detection, this algorithm can also be applicable to all kinds of complicated contact behavior and process.

\section{RESULTS ANALYSIS}

The calculation results of LS-DYNA to lead postprocessing software LS-PREPOST, we can get stress distribution of the roadway in different time, and solving process relationship of the stress and strain of each time.

\section{A. The maximum principal stress distribution analysis of different time}

Figure 3 the maximum principal stress distribution of each time. As can be seen from the graph, in the initial stress condition, with the axial stress increasing, rockmass around deep tunnels first appear stress concentration districts, but the distortion field surrounding other places is basically evenly unchanged (fig a). When the stress is bigger, the two edges of roadway start appear plastic zone, and sliding linear expansion (fig b). The cave walls plastic zone gradually transfixion, plastic zone area of vaults and corner parts of two bottom are larger, appears the zonal phenomenon of plastic area(fig c,d). Plastic deformation concentration on the area of the around hole, also is the deformation localization (fig e,f). Deformation area of strong concentration will lead to rock yield, rock attain to yield limit start to bate, and produce ruptured zone, The rock roadway of ruptured zone peripheral quickly produce to displacement to internal, making the area around of the broken rock were compacted, and becoming unruptured area. Broken away from the direction of the roadway surface to relay, creates new stress field, with the initial stress field superimposed, may make rock again burst, and more and more serious, thus forming obvious ribbon alternate cracking phenomena (figure $\mathrm{g}, \mathrm{h}$ ).

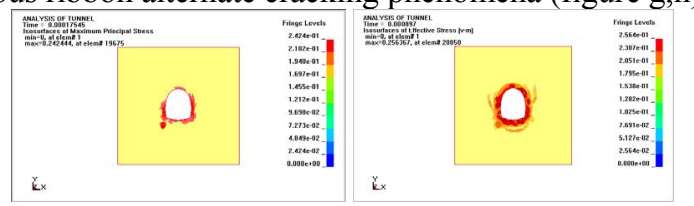

(b)

(a)
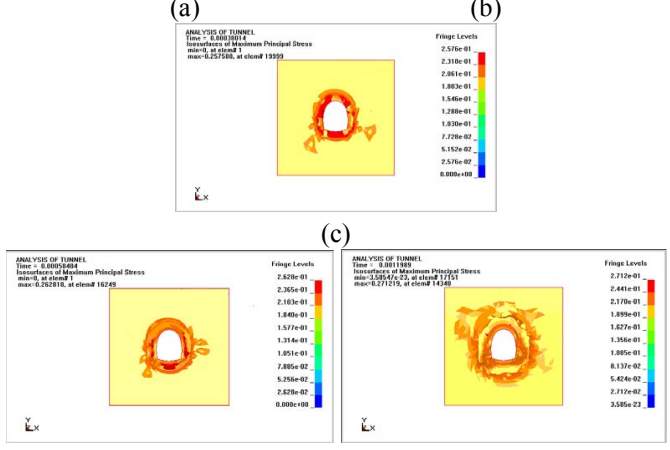

(d)

(e) 


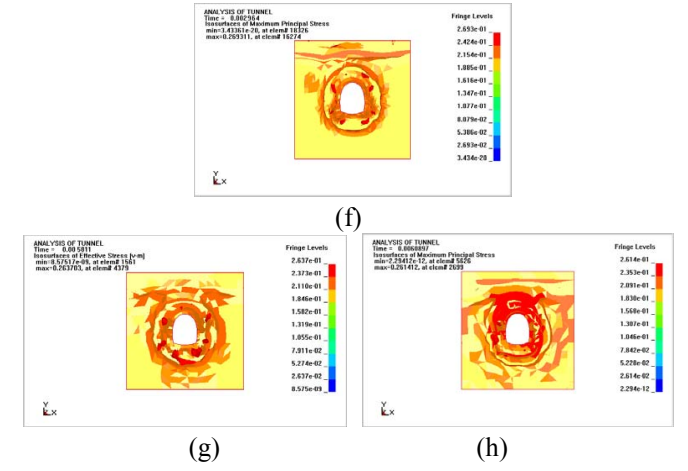

Figure 3. Stress distribution of each time

\section{B. Stress and strain curve analysis}

Figure 4 is the axial stress-time curves of different time in $\mathrm{z}$ direction loaded $\mathrm{x}, \mathrm{y}, \mathrm{z}$ axis. We Can see from figure 4, before loading time $30 \mathrm{~ms}$, the stress of each direction increases rapidly. When loading time for $30 \mathrm{~ms}$, stress peak value of $\mathrm{z}$ direction $50.8 \mathrm{MPa}$, about initial geostress of 2.07 times; rock around roadway begun to yield, at the moment, it caused around roadway rock to occur tensile stress damage, at the end of $30 \mathrm{~ms}$, the stress was the residual strength for materials.

Figure 5 is the axial strain-time curves of different time in $\mathrm{z}$ direction loaded $\mathrm{x}, \mathrm{y}, \mathrm{z}$ axis. By as mentioned above, in $30 \mathrm{~ms}$, the stress in surrounding rock reached peak value, then the strain reached maximum strain $2.76 \mathrm{e}-3$, exceeding the uniaxial compressive strength corresponding limit strain $2.3 \mathrm{e}-3$, rock began to break in ultimate tensile strain. After $30 \mathrm{~ms}$ strain decrease gradually, strain fluctuations as time increases, about $50 \mathrm{~ms}$ later, the wave amplitude is relatively minor.

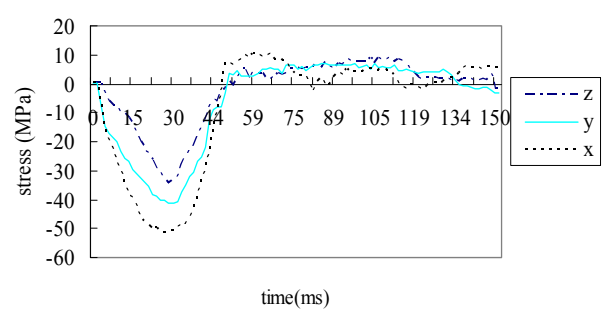

Figure 4. Stress-time curves

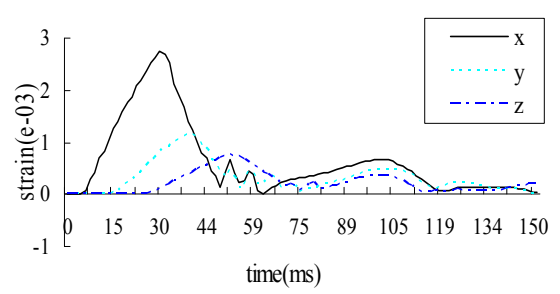

Figure 5. Strain-time curves
The above analysis shows that: in the initial stress conditions, the surrounding rock in deep excavation dynamic disturbance reaches a certain value, lead to rock produce the yield. After the rock reach to the yield limit, and begins to bate, forms rupture zone. The periphery of rock rupture zone is generated quickly displacement to the internal, making the fracture area of rock surrounding were compacted, and becoming unruptured area. Broken away from the direction of the roadway surface to relay, creates new stress field, with the initial stress field superimposed, may make rock again burst, and more and more serious, thus forming obvious ribbon alternate cracking phenomena

\section{CONCLUSION}

(1) The finite element numerical simulation software ANSYS dynamic analysis can effectively simulation of deep surrounding rock zonal disintegration phenomenon.

(2) Deep rock zonal disintegration phenomenon is accompanied by the yield damage, rock stress into submission status and damage, the residual stress state is the basis of surrounding rock zonal disintegration.

(3) In the initial stress conditions, the surrounding rock in deep excavation dynamic disturbance reaches a certain value, lead to rock produce the yield. After the rock reach to the yield limit, and begins to bate, forms rupture zone. The periphery of rock rupture zone is generated quickly displacement to the internal, making the fracture area of rock surrounding were compacted, and becoming unruptured area. Broken away from the direction of the roadway surface to relay, creates new stress field, with the initial stress field superimposed, may make rock again burst, and more and more serious, thus forming obvious ribbon alternate cracking phenomena

\section{ACKNOWLEDGMENTS}

The study presented in this paper was jointly funded by the National Natural Science Foundation of China (No. 50874020, 50934006), the 973 Program (No. 2007CB209407).

\section{REFERENCES}

[1] PAN Yi-shan; LI Ying-jie; Tang Xin, et al. Study on Zonal Desintegration of Rock [J]. Chinese Journal of Rock Mechanics and Engineering, 2007, 26 (S1) : 3 335-3 341.

[2] QIAN Qi-hu. The characteristic scientific phenomena of engineering response to deep rock mass and the implication of deepness [J]. Journal of East China Institute of Technology, 2004, 27 (1) : 1-5.

[3] Adams GR; Jager A J, et al. Petroscopic observations of rock fracturing ahead of stope faces in deep-level gold mines [J]. Journal of the South African Institute of Mining and Metallurgy, June, 1980: 204-209.

[4] Shemyakin EI; Kyrlenya M V; Reva V N,et al. Effect of zonal disintegration of Rocks around underground workings [J]. Dokl. Akad. Nauk. USSR,1986,289(5):1 088-1 094.

[5] Academic Department of China Association for Science and Technology. Effect of zonal disintegration of rock mass around deep tunnel [M]. Beijing: China Science and Technology Press, 2008,11.

[6] TANG Xin; PAN Yi-shan; ZHANG Meng-tao. Mechanism analysis of zonal disintegration in deep level tunnel [J]. Journal of Geological Hazards and Environment Preservation, 2006, 17 (4) : 80-84. 
[7] LI Ying-jie; PAN Yi-shan; LI Zhong-hua. Analysis of mechanism of zonal disintegration of rocks [J]. Chinese Journal of Geotechnical Engineering, 2006, 28 (9) : 1 124-1 128.

[8] GU Jin-cai; GU Lei-yu; CHEN An-min, et al. Model test study on mechanism of layered fracture within surrounding rock of tunnels in deep stratum $[\mathrm{J}]$. Chinese Journal of Rock Mechanics and Engineering, 2008, 27(3): 433-438.
[9] CHEN Long-wei. Three-dimensional elastic-plastic fluid dynamic media interface treatment and numerical simulation(Doctoral dissertation) [D]. Beijing, Beijing university of science and technology, 2003. 